\title{
A FORMAÇÃO INICIAL DE FUTUROS PROFESSORES DE MATEMÁTICA SOB A PERSPECTIVA DA RESOLUÇÃO DE PROBLEMAS
}

\section{INITIAL EDUCATION OF FUTURE MATHEMATICS TEACHERS FROM THE PERSPECTIVE OF PROBLEM SOLVING}

\author{
Manoel dos Santos Costa ${ }^{1}$ \\ Norma Suely Gomes Allevato ${ }^{2}$
}

\begin{abstract}
Resumo: Este artigo apresenta reflexões sobre a implementação da resolução de problemas enquanto metodologia de ensino e aprendizagem de Matemática, envolvendo licenciandos de uma universidade pública do estado do Maranhão. Nessa forma de trabalho, a construção de conhecimento se faz a partir de problemas (geradores), ponto de partida e orientação para o ensino e a aprendizagem de novos conceitos e/ou conteúdos. O estudo qualitativo desenvolvido mostrou a percepção dos licenciandos de que ela permite ao aluno vivenciar a construção de seu próprio conhecimento e aprender com profundidade as ideias matemáticas. Contudo, o futuro professor precisa vivenciá-la para compreender a dinâmida do trabalho, perceber conexões entre os conceitos e, assim, relacioná-los a diferentes tipos de problemas e ao cotidiano dos alunos.
\end{abstract}

Palavras-chave: Educação Matemática; Resolução de Problemas; Formação Inicial.

\begin{abstract}
The present paper shows reflections on the implementation of problem solving as a teaching and learning methodology of Mathematics, involving students of a public university in Maranhão state. In that kind of work, knowledge is built from (generator) problems, a starting point and guide to teach and learn new concepts and/or contents. The developed qualitative study showed that students became able to notice it allows them to experience the building of their own knowledge and learn mathematical ideas in depth. However, the future teacher must experience it to understand the work dynamics, to notice the connections between the concepts and, thus, relate them to different kinds of problems and to students' everyday activities.
\end{abstract}

Keywords: Mathematics Education; Problem Solving; Initial Education.

\section{Reflexões iniciais}

A formação de professores ganhou força a partir da década de 1990, destacandose, nesse ano, a Conferência Mundial de Educação para Todos, realizada em Jontiem, na Tailândia. Essa Conferência deu origem a diversas reformas educacionais e indicou,

\footnotetext{
${ }^{1}$ Doutor em Ensino de Ciências e Matemática pela Universidade Cruzeiro do Sul - UNICSUL. Atualmente é Professor da Educação Básica na Secretaria de Estado da Educação do Maranhão e da Educação Superior na Universidade Ceuma. São Luís, Maranhão, Brasil. E-mail: manolopromat@ hotmail.com

${ }^{2}$ Doutora em Educação Matemática pela Universidade Estadual Paulista Júlio de Mesquita Filho (UNESP) - Rio Claro. Docente e Pesquisadora do Programa de Pós-graduação em Ensino de Ciências e Matemática da Universidade Cruzeiro do Sul. São Paulo, São Paulo, Brasil. E-mail: normallev@gmail.com
} 
como prioridade, a Educação Básica e a formação de professores, que vêm ocupando lugar de destaque no cenário educacional e científico.

Desde então, pesquisadores de vários países (SHULMAN, 1997; PERRENOUD, 2002; TARDIF, 2014), e também do Brasil (PIRES, 2002; CURI, 2005; PIMENTA, 2008; CYRINO, 2013; GATTI, 2016) vêm desenvolvendo pesquisas sobre essa temática, apresentando resultados de investigação por meio de diferentes perspectivas teóricometodológicas.

Essas pesquisas buscavam responder à crise educacional instaurada nas décadas de 1980 e 1990, que exigiu reformas educacionais. Tais reformas ocorreram de modo a ampliar, entre outras coisas, os espaços de formação de professores, levando em consideração o que registra o relatório da Comissão Internacional sobre a Educação para o século XXI, organizada pela Unesco. Segundo o relatório, para melhorar a qualidade da Educação é essencial "melhorar o recrutamento, a formação, o estatuto social e as condições de trabalho dos professores", de modo que os professores possam "responder ao que deles se espera" (DELORS, 1999, p. 1).

De acordo com as ideias de Shulman,

a reforma escolar dependerá dos profissionais do ensino para avaliar e aprimorar a qualidade de seu trabalho, pois enquanto ela depender de autoridades burocráticas externas para fazer toda a avaliação, nunca afetará realmente o ensino da maneira que desejamos (SHULMAN, 1997, p. 186).

Nesse sentido, Perrenoud (2002) defende que só será possível formar professores se fizermos escolhas ideológicas, ou seja, "conforme o modelo de sociedade e de ser humano que defendemos, não atribuiremos as mesmas finalidades à escola e, portanto, não definiremos da mesma maneira o papel dos professores" (p. 12). E, ainda, que os princípios básicos para a formação de futuros professores não são neutros porque:

\footnotetext{
- Eles estão ligados a uma visão da escola que visa a democratizar o acesso aos saberes, a desenvolver a autonomia dos sujeitos, seu senso crítico, suas competências de atores sociais, sua capacidade de construir e defender um determinado ponto de vista.

- Esses princípios passam pelo reconhecimento da autonomia e da responsabilidade profissional dos professores, tanto individual quanto coletivamente (PERRENOUD, 2002, p. 15).
}

Portanto, a formação de professores deve promover o desenvolvimento pessoal dos licenciandos quanto à tomada de consciência de suas responsabilidades com seus alunos, e contribuir para que adquiram atitude reflexiva acerca do ensino e da aprendizagem. 
Para que a formação inicial seja um alicerce na prática dos futuros professores de forma abrangente e efetiva, é necessário que se obtenham conhecimentos de diferentes naturezas. Esses conhecimentos devem englobar fundamentos psicossociais ${ }^{3}$ que norteiam a atuação pedagógica e os aspectos legais do ensino expressos nas Políticas Educacionais e nas Diretrizes e Normas que orientam o desenvolvimento profissional. Defende-se uma formação ampla para o professor que, além do conhecimento da disciplina, considere o contexto onde seu trabalho será desenvolvido (CYRINO, 2013).

No bojo desses movimentos, o Ministério da Educação e Cultura - MEC, para impulsionar as reformas educacionais, lançou as Diretrizes Curriculares Nacionais - DCN para a formação inicial e continuada dos profissionais do magistério (BRASIL, 2015). O documento apresenta princípios, fundamentos, dinâmica formativa e procedimentos para as políticas, para o planejamento e a gestão dos programas e cursos de formação, e para os processos de avaliação e regulação das instituições que as ofertam. A reestruturação vem ao encontro do que defende Pimenta (2008): formar professores para "colaborar no processo de passagem dos alunos de se ver o professor como aluno ao ver-se como professor" (p. 20), isto é, de construir sua identidade de professor.

Segundo a autora, a docência representa um desafio que exige conhecimentos, competências e preparação específica para o seu exercício, para que os professores possam mobilizar os conhecimentos da teoria e da didática necessários à compreensão do ensino e da realidade social; além disso, que sejam reflexivos. Conforme aponta Tardif (2014), a formação inicial deve visar habilitar os futuros professores à sua prática docente e, com isso, fazer deles "práticos reflexivos".

\section{A formação inicial de futuros professores de Matemática}

Tendo em vista o que já foi destacado, as pesquisas sobre formação de professores têm aumentado nos últimos anos. Pouco a pouco, tem-se constatado uma preocupação dos pesquisadores da Educação Matemática em conhecer melhor a maneira como se dá o processo de ensino e aprendizagem, assim como em compreender a formação dos professores de Matemática, particularmente a formação inicial, que tem mostrado pontos críticos a serem superados.

\footnotetext{
${ }^{3}$ Que têm uma relação simultânea com a Psicologia individual e a vida social.
} 
DOI: http://dx.doi.org/10.33238/ReBECEM.2019.v.3.n.1.21905

Lampert e Ball (1999), citadas por Ponte (2002), a partir de uma investigação realizada nos Estados Unidos, traçaram um diagnóstico negativo da formação inicial de professores de Matemática. Segundo as autoras, os problemas desta formação resultam, dentre outras coisas, de os programas não considerarem as crenças, e os conhecimentos que os futuros professores trazem para sua formação; darem a impressão errônea de que, para ensinar, é preciso pouco mais do que senso comum e pensamento vulgar, ou seja, não mostram aos licenciandos a necessidade de um conhecimento profissional e por não darem a devida atenção ao conhecimento didático e à formação profissional.

Curi (2005) destaca que é preciso refletir sobre as crenças nos programas de formação para que os futuros professores não passem por elas, sem modificar sua visão inicial, muitas vezes inadequada, sobre o ensino e a aprendizagem da Matemática, pois já trazem consigo algumas crenças negativas e ultrapassadas (por exemplo, a de que Matemática é para poucos, de que para ensinar/aprender Matemática é preciso simplesmente repetir/treinar). Dessa forma, não basta simplesmente mudar ou manter essas crenças; elas precisam ser discutidas durante a formação inicial. Ainda de acordo com a autora, as crenças influenciam no conhecimento do professor, pois interferem na construção de novos conhecimentos e interagem com o que eles sabem de Matemática, influenciando assim na tomada de decisão e na ação do professor para ensinar Matemática.

Assim, cabe a refletir sobre o papel das licenciaturas no processo de formação, que deve envolver, além da dimensão profissional futura do professor, aspectos ligados às crenças trazidas do período de escolarização.

Portanto, os programas de formação inicial de professores de Matemática não podem se resumir a meras prescrições de um conjunto de saberes. Segundo Fernandes e seus colaboradores (1997), não é correto pensar que formar professores seja um processo em que fundamentalmente se "dizem" e se "enunciam" princípios que geralmente são aceitos e que dificilmente se podem rejeitar. Também não é correto pensar que formar professores seja um processo que pode ser desenvolvido somente "ensinando matérias", sem considerar as questões de natureza social e cultural.

Nesse sentido, Ponte (2002, p. 3) afirma que "um curso de formação inicial de professores de Matemática deve ser necessariamente diferente de um curso de Matemática que visa formar matemáticos para se dedicarem prioritariamente à 
DOI: http://dx.doi.org/10.33238/ReBECEM.2019.v.3.n.1.21905

investigação". Ainda segundo o autor a formação inicial de professores visa formar profissionais competentes para o exercício da profissão.

Corroborando com essas ideias, Pires (2002) destaca que, ao se trabalhar com a formação inicial de professores, parte-se do princípio que todo licenciando, durante sua formação, teve oportunidade de se desenvolver como pessoa e como cidadão o suficiente para vir a ser um bom professor, mas que nem sempre isso acontece. A autora destaca três eixos que deveriam servir de princípio orientadores em um programa de formação de professores.

[...] (1) a concepção de competência é nuclear na orientação do curso de formação inicial de professores; (2) é imprescindível que haja coerência entre a formação oferecida e a prática esperada do futuro professor; (3) a pesquisa é elemento essencial na formação profissional do professor (PIRES, 2002, p. 45).

Do ponto de vista de Pires (2002), Pimenta (2008) e Cyrino (2013), a organização de um programa de formação de professores não pode ter como ponto de partida apenas um conjunto de disciplinas, como vem sendo feito, mas deve buscar também, o desenvolvimento de competências e saberes profissionais que se pretende que o futuro professor construa ao longo de sua trajetória de formação.

Sendo assim, dominar o conteúdo de ensino é condição fundamental, mas não suficiente, ao professor, especialmente nos dias atuais. Além disso, adotando a premissa de que o pensar orienta o fazer docente (GARCIA, 2009), a prática educativa e as teorias educacionais devem caminhar juntas na formação inicial do professor. Nesse contexto, parece, no mínimo, estranho que um curso, cuja especificidade seja formar professores, não os torne basicamente preparados para lidar satisfatoriamente com o trabalho em sala de aula, trabalho que, nos dias atuais, tem seu grau de complexidade ampliado por novas propostas e inovações educacionais (GATTI, 2016).

Ainda atualmente, alguns ambientes de formação inicial de professores estão centrados no paradigma da racionalidade técnica, ou seja, em uma concepção epistemológica da prática. Isso implica primeiramente trabalhar com os conteúdos a serem ensinados, para depois trabalhar os conhecimentos pedagógicos, isto é, com as disciplinas que discutem os princípios educacionais (leis, teorias e suas aplicações práticas) de como atuar em sala de aula. Os cursos de formação inicial de professores precisam repensar essa perspectiva de racionalidade técnica e dedicar-se mais aos saberes 
pedagógicos em momentos de prática, isto é, em momentos de aplicação (CYRINO, 2013).

Não podemos esquecer que os atuais alunos da Educação Básica (Ensinos Fundamental e Médio) são bem diferentes daqueles de vinte ou trinta anos atrás. Encontramos alunos utilizando diferentes recursos em sala de aula (por exemplo, os celulares), o que, às vezes, torna-se um problema para o professor; porém, esses recursos podem ser utilizados a favor da aprendizagem. Além disso, o novo professor irá depararse com as diferenças individuais, com a diversidade, com os alunos portadores de necessidades especiais de todos os tipos.

Por tudo isso, os programas de formação terão que (re)pensar em mudanças quanto à concepção das práticas de aprendizagem e as práticas docentes do futuro professor, implementando um currículo explícito e específico, estruturado para que se possam estabelecer conexões entre o que se estuda na faculdade (teoria) e a realidade da atuação docente (prática).

Em suma, os programas de formação de professores de Matemática desempenham algumas funções, das quais destacamos: (i) a de ajudar os futuros professores a analisarem as suas concepções sobre a Educação, sobre o ensino de Matemática e sobre a Matemática; (ii) a de ajudá-los a desenvolver seus conhecimentos de Matemática, de Pedagogia e da Educação como um todo; e (iii) a de acompanhar os (futuros) professores nas suas experiências formativas, de maneira que, a partir delas, possam aplicar, integrar, relacionar ou questionar os conhecimentos teóricos que adquirirem na sua formação inicial, atribuindo-lhes, assim, um significado real. Portanto, não se trata simplesmente de "prescrever" o que pode ou não fazer o futuro professor (FERNANDES et al., 1997).

Assim sendo, a formação de professores de Matemática deve considerar conhecimentos, concepções, crenças e práticas e suas relações. Deve desafiar suas perspectivas com relação à sua aprendizagem, em particular à aprendizagem matemática. Além disso, os cursos de formação têm de ajudá-los a construir profunda compreensão dos conceitos e conteúdos matemáticos que fazem parte do currículo escolar.

Pesquisas (SANTOS et al., 2005) e documentos oficiais (MARANHÃO, 2014; BRASIL, 1998, 2015) nos revelam que a construção e compreensão dos conteúdos matemáticos definidos nos currículos da formação inicial devem assumir um papel importante, uma vez que é também na aprendizagem de conteúdos que se dá a construção 
DOI: http://dx.doi.org/10.33238/ReBECEM.2019.v.3.n.1.21905

e o desenvolvimento de saberes, principalmente quando existe uma interação entre a construção desses conhecimentos através das experiências práticas e a tentativa de racionalização de "organização" e de reconstrução teórica desses mesmos conhecimentos.

Além disso, de acordo com Shulman (1997), cada área do conhecimento tem uma especificidade própria, o que justifica a necessidade de se estudar o conhecimento do futuro professor a respeito do que vai ensinar, a fim de ajudá-lo a compreender o que vai ensinar com base em diferentes perspectivas.

\section{A resolução de problemas na formação inicial de futuros professores de Matemática}

As discussões sobre a Resolução de Problemas na formação inicial de professores de Matemática, tanto no Brasil (NUNES, 2010; COSTA, 2012) como em outros países (SERRAZINA; OLIVEIRA, 2002), são bastante pontuais. Nunes (2010) e Costa (2012) sugerem que seja feito um trabalho com os futuros professores de modo a propiciar reflexão e análise sobre as potencialidades que a Resolução de Problemas oferece no sentido de incrementar a aprendizagem e melhorar os processos de ensino de Matemática.

Serrazina e Oliveira (2002), em uma revisão bibliográfica realizada em Portugal, no âmbito da formação inicial, identificaram dois grupos: o primeiro centrado na resolução de problemas e o segundo em tarefas de investigação. Com relação à Resolução de Problemas, foco de nosso estudo, foram identificados quatros pontos de convergência: (1) pode-se ensinar os futuros professores a resolver problemas e eles desenvolvem uma atitude positiva em relação à resolução de problemas; (2) há dificuldades em alguns aspectos da resolução de problemas - compreensão, generalização e argumentação; (3) a deficiência de conhecimentos matemáticos influencia na capacidade de resolução de problemas; e (4) os módulos de ensino sobre resolução de problemas parecem não ser suficientes para que os futuros professores mudem suas concepções sobre a natureza da Matemática e do seu ensino e terem vontade ou capacidade para alterar suas práticas relativamente aos modelos de ensino tradicionais, não raro praticados pelos seus professores ao longo da sua escolaridade.

Vale ressaltar que, no início dos anos de 1980, com o declínio da Matemática Moderna, a Resolução de Problemas despontou como possível solução para os problemas 
do ensino de Matemática; mas os professores tinham dificuldades em discernir os processos utilizados na resolução de problemas e os fundamentos do seu ensino.

Ainda hoje, apesar de a Resolução de Problemas ser muito discutida por estudiosos da área, os professores ainda sabem pouco sobre como trabalhá-la com seus alunos. Por isso, os pesquisadores (VALE, 1997; ONUCHIC, 1999; NUNES, 2010; COSTA; ALLEVATO, 2015) realçam a importância de proporcionar aos futuros professores experiências que desenvolvam seus conhecimentos "em" e "sobre" a Matemática e "em" e "sobre" a Resolução de Problemas.

Sendo assim, a formação inicial de professores de Matemática deveria incluir atividades voltadas à aprendizagem através da resolução de problemas, para que os licenciandos vivenciem experiências a serem colocadas em sua prática de sala de aula. A Resolução de Problemas como metodologia de ensino e aprendizagem de Matemática nos permite desenvolver processos de pensamento nos alunos, suas capacidades, saberes e competências (COSTA; ALLEVATO, 2015). Além disso, é fundamental, sobretudo, na Educação Básica por se tratar de uma atividade de incidência interdisciplinar que abrange diversas disciplinas e pode desenvolver as capacidades que são necessárias à formação global dos estudantes. E não se descarta sua importância também na Educação Superior, confome se evidencia em algumas pesquisas (BASTOS, 2013).

Vale (1997) consideram que os programas de formação inicial de professores de Matemática devem proporcionar aos licenciandos, o desenvolvimento de experiências para o ensino e a aprendizagem fundamentados na resolução de problemas; resolver problemas diversificados e conhecer dificuldades, desempenhos, convicções, concepções e atitudes dos futuros professores perante a resolução de tais problemas. Segundo a autora, esse período de formação é "privilegiado, pois pode contribuir favoravelmente para o desenvolvimento das concepções dos futuros professores" (p. 2), e deve proporcionar um ambiente de aprendizagem em que eles tenham amplas oportunidades para resolver uma grande variedade de problemas. Esse ambiente deverá confrontá-los com as mesmas atividades e experiências que deverão propor aos seus futuros alunos.

De acordo com as propostas do NCTM (2014), para melhorar o ensino da Matemática o professor deve analisar aquilo que ele e seus alunos fazem e de que modo isso afeta, ou não, a aprendizagem. Segundo o documento, o papel do professor é envolver os estudantes em tarefas que promovam o raciocínio e a resolução de problemas. Um 
DOI: http://dx.doi.org/10.33238/ReBECEM.2019.v.3.n.1.21905

professor ativo proporciona desafios apropriados, encoraja a perseverança na resolução de problemas e favorece um esforço que resulta na aprendizagem matemática.

Para que os alunos aprendam matemática com compressão têm que haver oportunidades para eles se envolverem regularmente em atividades que se centrem no raciocínio e na resolução de problemas e que viabilizem múltiplas abordagens e estratégias diversificadas de resolução (NCTM, 2014, p. 23).

Essas tarefas devem ser desenvolvidas a partir das experiências individuais e coletivas de construção de significado via resolução de problemas. Desse modo, um ensino eficaz de Matemática favorece o discurso entre os alunos de modo a construírem uma compreensão partilhada das ideias matemáticas recorrendo à análise e à compreensão das suas abordagens e dos seus argumentos.

Ainda, Vale (1997) enfatiza que, o que se pretende com a Resolução de Problemas é desenvolver nos futuros professores seus conhecimentos, seu gosto e confiança para que se tornem resolvedores criativos e independentes, capazes de estimular a criatividade dos seus alunos através da organização e planejamento de suas atividades em sala de aula. Sendo assim, os programas de formação devem contribuir, entre outras coisas, para aprofundar os conhecimentos, as competências e os saberes dos futuros professores de Matemática sobre a Resolução de Problemas, pois estes podem encontrar-se mais receptivos para a aprendizagem e para mudanças em suas concepções do que os professores que já estão atuando como docentes. Conhecendo como reagem os licenciandos e o que sabem sobre Resolução de Problemas, mais facilmente se pode ir ao encontro de uma metodologia de ensino que os ajude a ultrapassar suas dificuldades, influenciando positivamente o seu ensino.

Portanto, a finalidade de abordar e utilizar a Resolução de Problemas como metodologia de ensino e aprendizagem na formação de futuros professores de Matemática é desenvolver os conhecimentos e as práticas dos professores, não só para que possam reproduzi-las, mas também para prepará-los para uma prática que seja dinâmica, interativa e reflexiva. É necessário que se investiguem em um contexto de sala de aula as capacidades, convicções, atitudes e desempenho dos resolvedores de problemas por meio das atividades de resolução de problemas (ALLEVATO; ONUCHIC, 2014). 
DOI: http://dx.doi.org/10.33238/ReBECEM.2019.v.3.n.1.21905

\section{Resolução de problemas: uma metodologia ativa no processo de ensino e aprendizagem}

O ensino e a aprendizagem de Matemática através da Resolução de Problemas, tal como é apresentada por Allevato e Onuchic (2014), é uma metodologia diferente daquele trabalho em que regras de "como fazer" são privilegiadas. Trata-se de uma metodologia em que a construção de conhecimento se faz a partir de problemas (geradores) propostos como ponto de partida e orientação para o ensino e a aprendizagem de novos conteúdos.

Segundo Van de Walle (2009), professores de Matemática competentes devem envolver em sua prática pedagógica de sala de aula, quatro componentes básicos: a valorização da disciplina Matemática em si mesma, ou seja, "o fazer matemática"; a compreensão de como os alunos aprendem e constroem ideias; a habilidade em planejar e selecionar atividades de modo que os estudantes aprendam Matemática num ambiente de resolução de problemas; e a habilidade em integrar a avaliação ao processo de ensino e aprendizagem.

Desse modo, ensinar Matemática, utilizando resolução de problemas enquanto metodologia de ensino e aprendizagem, não é uma tarefa fácil, pois não basta apresentar um problema e "ficar sentado", esperando que alguma mágica aconteça. Mas, também, não significa dizer que existe uma forma rígida para usufruir dessa metodologia nas aulas de Matemática. Allevato e Onuchic (2014) sugerem que o ponto de partida para a aprendizagem de novos conceitos se faça a partir de problemas, os quais chamam de problemas geradores. Os alunos são desafiados a resolver um problema antes de lhes ter sido apresentado o conteúdo mais adequado ou indicado à sua resolução. Começam trabalhando individualmente, a partir de seus conhecimentos prévios; depois, em pequenos grupos de alunos, discutem e avançam na resolução; então, expõem suas resoluções em plenária, e com toda a classe chegam a um consenso sobre a resolução do problema. Finalmente, o professor assume o "comando" e formaliza o conteúdo matemático envolvido no problema, e que foi planejado para ser ensinado naquela aula.

Os conteúdos matemáticos desenvolvidos dessa forma, segundo as autoras, fazem sentido para o aluno, que passa a ser protagonista na construção de seu próprio conhecimento. Ao contrário de outras práticas em sala de aula em que os problemas são propostos no final de cada conteúdo, com essa metodologia, os problemas são propostos aos alunos antes de lhes ter sido apresentado formalmente o conteúdo matemático e dessa 
DOI: http://dx.doi.org/10.33238/ReBECEM.2019.v.3.n.1.21905

forma, a aprendizagem se realiza a partir e no decorrer (através) da resolução do problema. Esse caminho para ensinar Matemática torna o ato de resolver problemas uma parte integrante no processo da aprendizagem matemática; isso significar que os alunos aprendem matemática enquanto estão resolvendo problemas.

Vale ressaltar que o conteúdo deve estar de acordo com o ano de escolaridade em que se encontram os alunos e com os objetivos pretendidos para aquela aula.

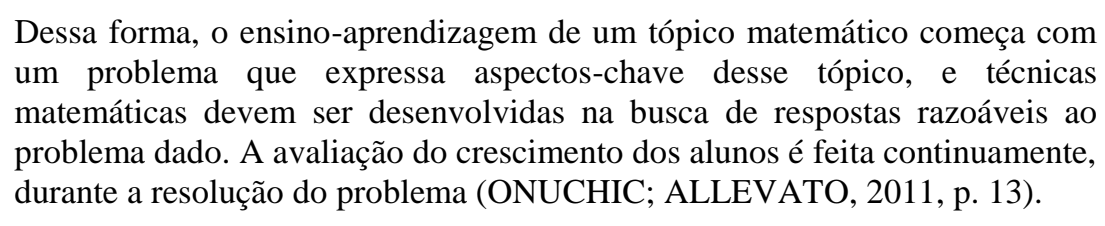

Além disso, essa metodologia de ensino e aprendizagem contempla ações pedagógicas (interação entre alunos; entre alunos e professor) que promovem a busca por informação, investigação, experimentação e renovação do interesse e da motivação dos alunos, aspectos que serão analisados no presente artigo.

\section{Orientações metodológicas e os sujeitos da pesquisa}

O presente estudo registra um trabalho de natureza qualitativa, em que buscamos retratar de forma minuciosa o fenômeno observado; interpretando e analisando os dados por descrições detalhadas. Com esse tipo de pesquisa, os sujeitos são mais participativos e, portanto, ela é menos controlável, envolve a obtenção dos dados descritivos, obtidos no contato direto do pesquisador com a situação estudada e enfatiza mais o processo que o produto (LÜDKE; ANDRÉ, 2017).

Os dados (problemas resolvidos), que serão apresentados na próxima seção, foram coletados com 19 alunos que cursavam o primeiro período de licenciatura em Matemática em uma universidade pública no Estado do Maranhão, em doze encontros de formação, com 4 horas cada, totalizando 48 horas de estudos, discussões e reflexões. Foram utilizados a observação participante em que "a coleta [dos dados] é realizada junto aos comportamentos naturais das pessoas quando estas estão conversando, ouvindo, trabalhando, estudando em classe, brincando, comendo..." (FIORENTINI; LORENZATO, 2012, p. 107); e a análise documental, que é realizada com documentos originais escritos "que ainda não receberam nenhum tratamento analítico" (HELDER, 2006, p. 1). Em nosso trabalho, essa análise foi realizada nas resoluções escritas dos 
DOI: http://dx.doi.org/10.33238/ReBECEM.2019.v.3.n.1.21905

problemas apresentados pelos futuros professores participantes da formação, que serão identificados como $\mathrm{A}_{1}, \mathrm{~A}_{2}, \ldots, \mathrm{A}_{19}$, com intuito de resguardar suas identidades.

\section{Descrição e análise dos problemas trabalhados na formação}

A Resolução de Problemas é uma das linhas de pesquisas que vem sendo desenvolvida por pesquisadores de diversos grupos (GTERP - UNESP; GPEAEM UNICSUL; GPECEM - UNICEUMA) em todos os níveis de ensino. De um modo geral esses grupos têm em comum o objetivo de refletir sobre e analisar as possibilidades que a Metodologia de Ensino-Aprendizagem-Avaliação de Matemática através da Resolução de Problemas oferece no sentido de incrementar a aprendizagem e melhorar os processos de ensino, assim como promover o aperfeiçoamento das práticas pedagógicas dos professores em sala de aula.

A proposta dos encontros de formação foi abordar e discutir a resolução de problemas, enquanto metodologia de ensino e aprendizagem. Para que os licienciandos pudessem vivenciar na prática a metodologia apresentamos problemas envolvendo o conteúdo proporcionalidade. Para iniciar as discussões, foi apresentado o seguinte problema:

Quadro 1: Problema envolvendo o conteúdo de proporcionalidade

\section{SUPER-MERCADO}

Uma arquiteta desenhou uma planta de um piso para um supermercado. O mercado é retangular com um comprimento que é o dobro da largura. O comprimento atual do mercado é largura atual é ___ _ . Na planta, a arquiteta desenhou o comprimento com ____ e a largura com _. Ela usou a escala equivalente a

a) Leia o enunciado.

b) Observe os números do quadro.

$\begin{array}{llllll}1 \mathrm{~cm} & 7 \mathrm{~cm} & 14 \mathrm{~cm} & 25 \mathrm{~m} & 175 \mathrm{~m} & 350 \mathrm{~m}\end{array}$

c) Coloque os números nas lacunas onde você achar que eles se encaixam melhor.

d) Leia novamente o enunciado. Os números fazem sentido?

e) Explique como você pensou para colocar os números corretamente nos espaços em branco.

f) Para você, essa situação é um problema? Por quê?

Fonte: Adaptação de Krulik e Rudnick (2002)

Questionamos aos alunos se a situação apresentada foi de fato um problema para eles. Dos 19 participantes que responderam, 17 disseram que foi um problema, apenas 1 respondeu que não foi; e o outro não respondeu. A seguir, algumas das justificativas: 
DOI: http://dx.doi.org/10.33238/ReBECEM.2019.v.3.n.1.21905

Figura 1: Resposta apresentada por A9

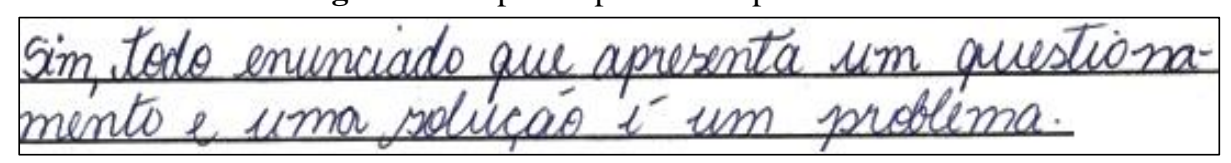

Fonte: Dados da pesquisa

Figura 2: Resposta apresentada por A4

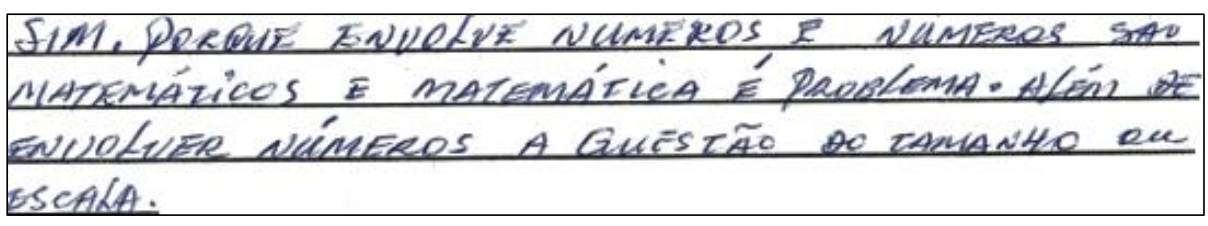

Fonte: Dados da pesquisa

Figura 3: Resposta apresentada por A5

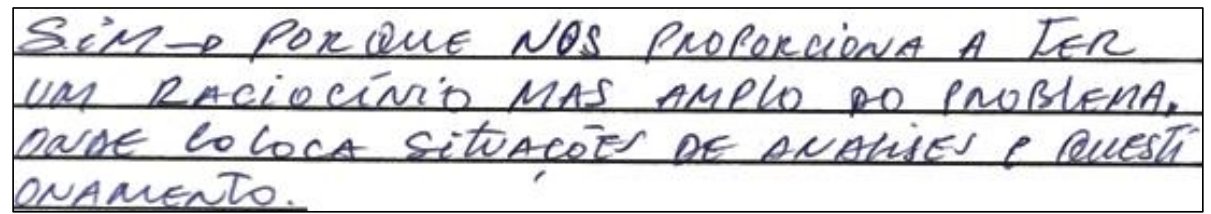

Fonte: Dados da pesquisa

Figura 4: Resposta apresentada por A6

\begin{tabular}{|c|}
\hline 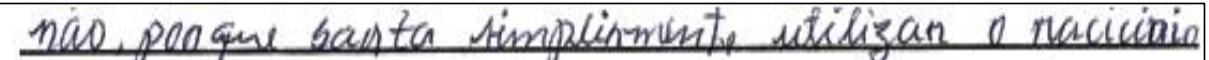 \\
\hline 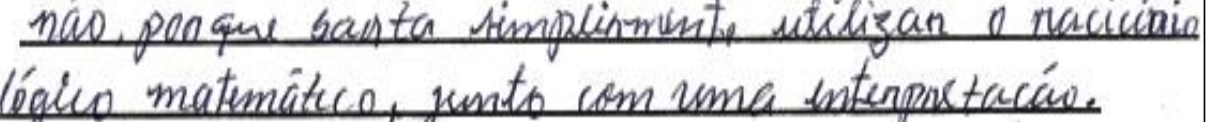 \\
\hline
\end{tabular}

Fonte: Dados da pesquisa

Observando as respostas dadas pelos futuros professores, percebemos que existem diferenças em relação ao que vem a ser um problema matemático para eles. Provavelmente, isso tenha ocorrido porque os licenciandos já carregam consigo algumas crenças desde a sua formação na Educação Básica, ou seja, muitas delas podem ser o reflexo da forma como seus professores desenvolveram os conteúdos em sala de aula.

A9 justificou sua resposta expressando que foi um problema por se tratar de um questionamento que precisa de solução. Ou seja, para ele, uma atividade é um problema matemático quando apresenta questionamentos.

Para A4, a situação apresentada foi um problema por apresentar números, isto é, para ele, tudo o que apresenta números é um problema. Os alunos A5 e A6 nos apresentaram justificativas em que um discorda do outro. Para A5, foi um problema por exigir o raciocínio para a compreensão do problema, enquanto que para A6 não foi um problema exatamente por exigir apenas o raciocínio e a interpretação para entendimento e resolução do mesmo. 
DOI: http://dx.doi.org/10.33238/ReBECEM.2019.v.3.n.1.21905

Percebemos fortemente o caráter inacabado do que vem a ser um problema para esses futuros professores, mas vale ressaltar que algumas dessas crenças manifestadas por eles, de que "tudo que envolve número é problema" e que "todo enunciado que apresenta questionamento é um problema", em relação aos problemas matemáticos, provavelmente são trazidas de sua experiência escolar e manifestadas/influenciadas pelos seus antigos professores, conforme apontado por Curi (2005) e Garcia (2009).

Vejamos outra resposta, esta apresentada por A15. Este licenciando utiliza o termo "dificuldade" em sua justificativa, o que a diferencia das manifestações dos demais participantes:

Figura 5: Resposta apresentada por A15

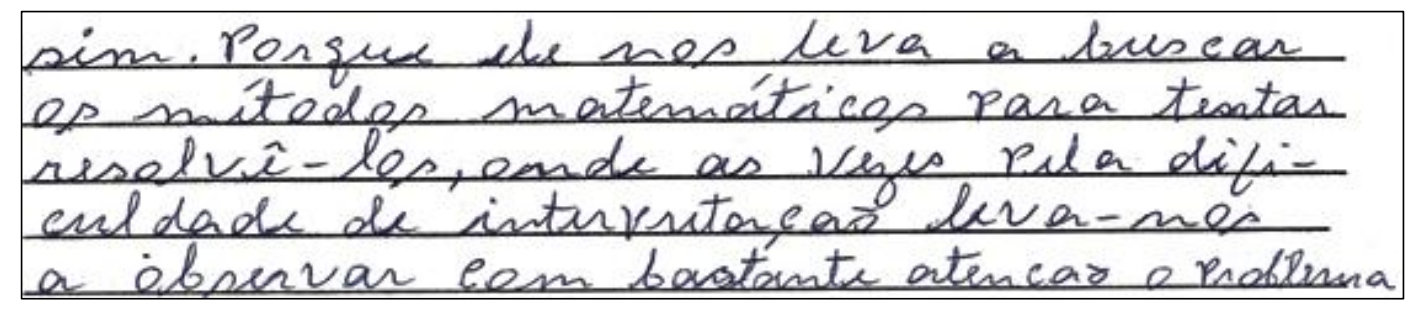

Fonte: Dados da pesquisa

O estudante justificou sua resposta dizendo que, para resolver o problema, precisou buscar métodos matemáticos. Nesse caso, entendemos que o aluno buscou ferramentas dentro do que já havia estudado na Matemática. Concordamos com a justificativa dada por A15 quando ele aponta que um problema exige que busquemos métodos matemáticos para resolvê-lo, assim como concordamos com A5, ao apontar que precisamos utilizar o raciocínio para solucionar um problema. No entanto, uma situação, para ser um problema, precisa mais que isso. Ou seja, um problema “[...] é tudo aquilo que não se sabe fazer, mas que se está interessado em resolver" (ONUCHIC, 1999, p.215). Além disso, um problema exige a elaboração de estratégias que possibilitem o aprimoramento do conhecimento durante a construção de sua resolução.

Após os futuros professores terem acabado de justificar se a situação "o supermercado" era ou não um problema para eles, questionamos: O que é um problema matemático? Algumas respostas dadas vêm ao encontro das justificativas apresentadas por eles na questão anterior. De acordo com os protocolos que apresentaremos a seguir, percebemos que eles não têm clareza sobre o assunto e novamente confirmamos algumas crenças já manifestadas anteriormente.

Segundo A12, um problema é matemático quando envolve números e cálculos. 
DOI: http://dx.doi.org/10.33238/ReBECEM.2019.v.3.n.1.21905

Figura 6: Resposta apresentada por A12

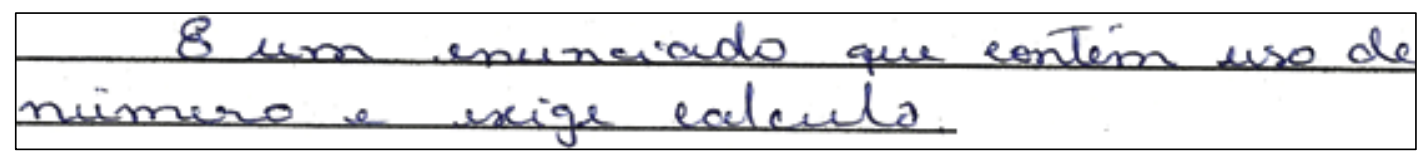

Fonte: Dados da pesquisa

Para outros, um problema matemático exige raciocínio e pensamento:

Figura 7: Resposta apresentada por A3

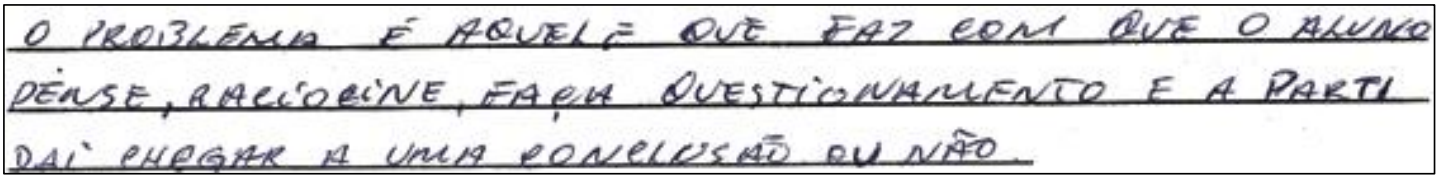

Fonte: Dados da pesquisa

Para A9 e A16, um problema é matemático quando envolve questionamentos:

Figura 8: Resposta apresentada por A9

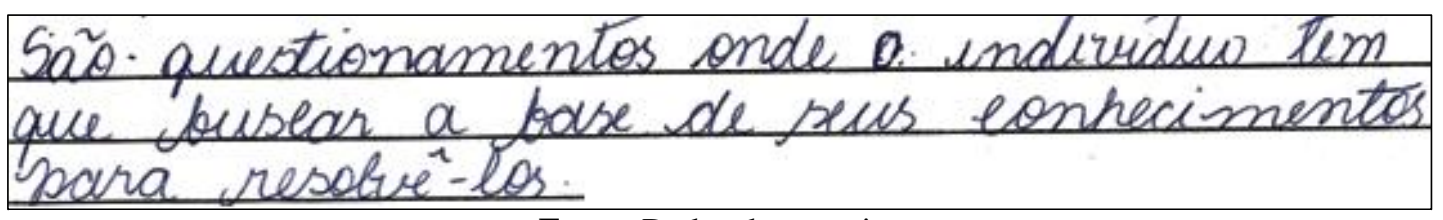

Fonte: Dados da pesquisa

Figura 9: Resposta apresentada por A16

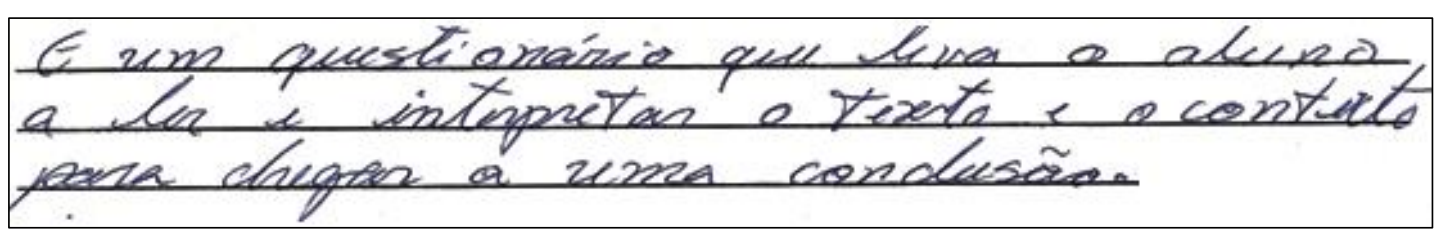

Fonte: Dado da pesquisa

De fato, um aluno também precisa ir à busca de seus conhecimentos matemáticos para resolver um problema matemático. O licenciando A2 nos apresentou uma resposta diferente das demais; para ele, um problema é:

Figura 10: Resposta apresentada por A2

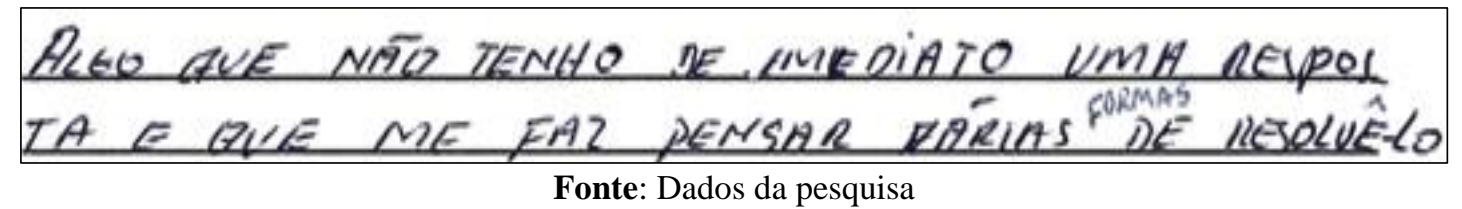

Fonte: Dados da pesquisa 
DOI: http://dx.doi.org/10.33238/ReBECEM.2019.v.3.n.1.21905

A resposta apresentada por A2 vem ao encontro do que defendemos nesta pesquisa sobre o que vem a ser um problema, ou seja, uma atividade matemática é considerada como problema quando o aluno demonstra interesse em resolvê-la e ainda não possui conhecimentos disponíveis para tal procedimento.

Para A18, um problema matemático é:

Figura 11: Resposta apresentada por A18

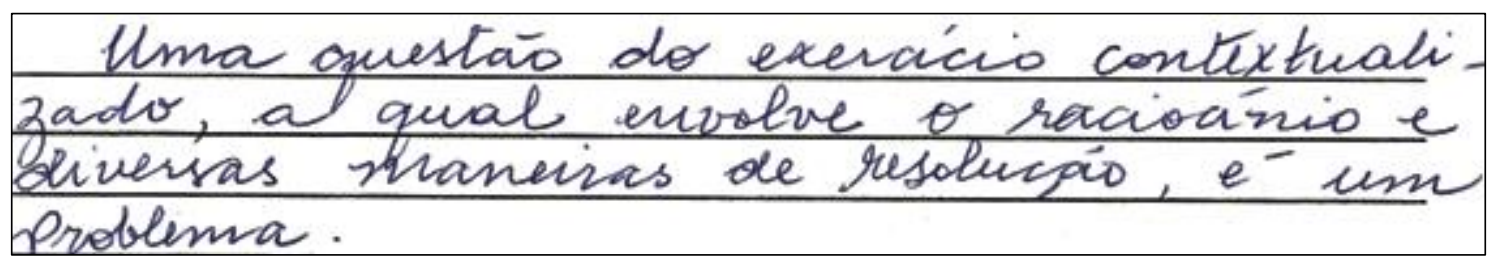

Fonte: Dados da pesquisa

Esse participante associou um problema matemático a um exercício contextualizado, em formato de texto, envolvendo ou não números, que exige raciocínio para sua resolução.

Portanto, com as respostas apresentadas pelos futuros professores, percebemos que não houve consenso entre eles sobre o que é um problema matemático; acreditamos que isto se deve possivelmente ao fato de que eles carregam consigo diferentes experiências como alunos, que condicionam em crenças em relação à Matemática e seu ensino, e também em relação à resolução de problemas. Podemos perceber, pelas respostas ao questionamento que será apresentado a seguir, que provavelmente as crenças se manifestam nos licenciandos também por sua vivência em um determinado conteúdo.

Você se lembra de, em algum momento de sua formação básica (Ensinos Fundamental e Médio), ter estudado os conteúdos matemáticos envolvendo resolução de problemas?

Foi solicitado, caso a resposta fosse sim, que descrevessem de que modo isso foi feito. Os participantes responderam que sim, que estudaram os conteúdos matemáticos envolvendo a resolução de problemas, e justificaram dizendo que:

Figura 12: Resposta apresentada por $\mathrm{A} 8$

1E EXPLICA BASTANTE O ASSUNTO, DAUA
ALGUNS EXEANCLOS NO CUADRO, POSTHRIO-
WENTE PASSA AS ATIVIDADFS.

Fonte: Dados da pesquisa 
Figura 16: Resposta apresentada por A6

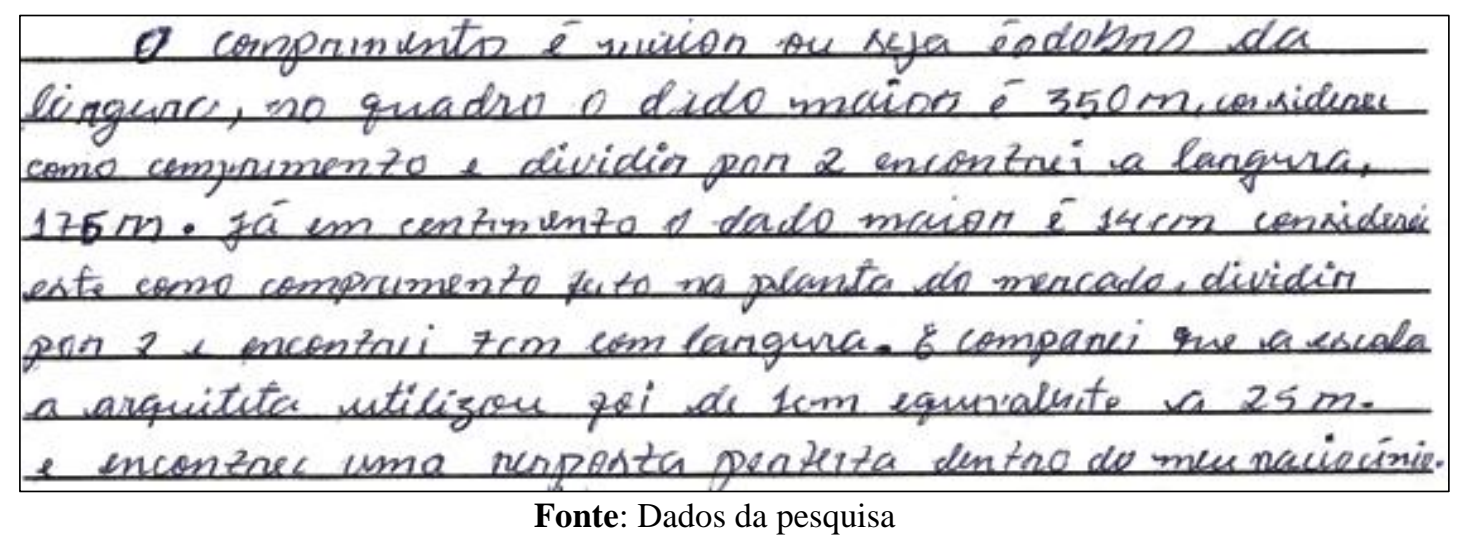

Figura 17: Resposta apresentada por A9

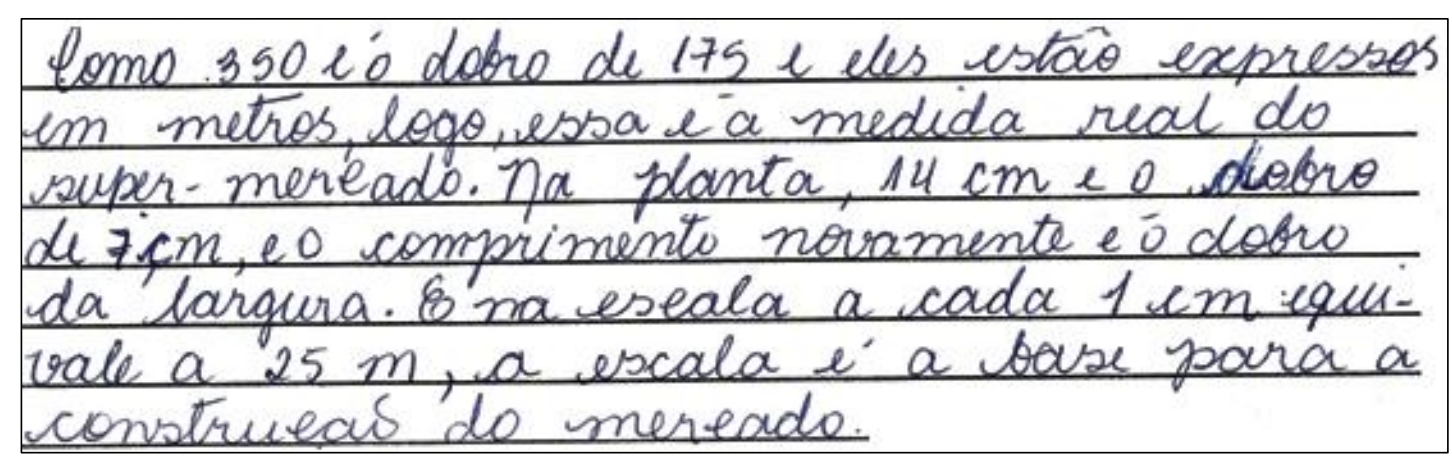

Fonte: Dados da pesquisa

Observando os três últimos protocolos, percebemos que todos usaram o conceito de proporcionalidade. Também observamos que cada licenciando procurou resolver o problema de acordo com os dados fornecidos, ou seja, utilizou o raciocínio considerando o tamanho real do "super-mercado" e o tamanho do desenho, em que o comprimento é o dobro da largura. Alguns fizeram menção à escala, ou seja, ao tamanho real relacionando com o tamanho do desenho.

Outro aspecto a ser destacado é que a maioria desses futuros professores soube aplicar o conceito de proporcionalidade, mas não soube falar sobre ele. Um dos participantes apresentou uma justificativa diferente das demais, conforme podemos observar no próximo protocolo: 
Figura 18: Resposta apresentada por A15

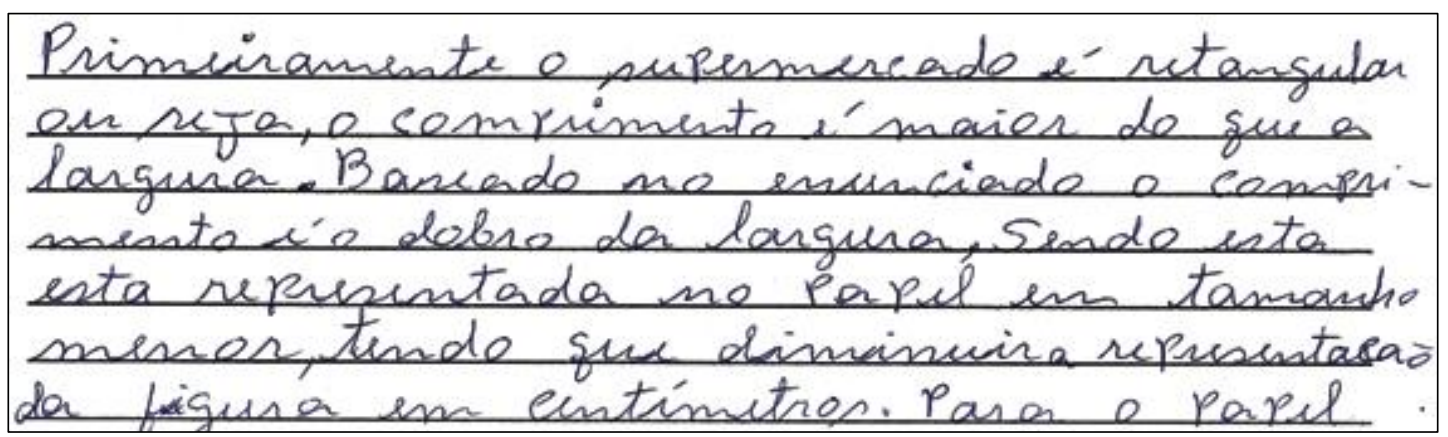

Fonte: Dados da pesquisa

Nessa explicação, A15 afirmou que o "super-mercado" é retangular por apresentar o comprimento maior que a largura. Isso sugere que, para ele, só é um retângulo o quadrilátero que apresenta essa característica. Por essa afirmação, um quadrado não é um retângulo, pois nele as medidas de comprimento e largura são iguais. Entretanto, o correto é considerar que um retângulo é um quadrilátero plano convexo que possui 4 ângulos congruentes. O saber matemático manifestado pelo licenciando explicita um estereótipo construído com frequência nas aulas de Matemática, a partir de ideias preconcebidas resultantes de falsas generalizações ou da falta de conhecimento sobre o assunto. Ressalte-se, ainda, que esse participante não usou o conceito de proporcionalidade.

Esse tipo de "confusão" cometido por esse licenciando deve ser considerado, conforme apontam Pires (2002) e Pimenta (2008), nos programas de formação de professores, aos futuros professores o desenvolvimento de competências e saberes profissionais. De acordo com as autoras, para que isso ocorra, é imprescindível que haja coerência entre a formação oferecida e a prática que será desenvolvida pelos professores, ou seja, a formação desses futuros profissionais não deve ter como ponto de partida somente um conjunto de disciplinas específicas da área, mas as demandas de seu ambiente de trabalho.

A seguir, apresentamos um dos problemas que foi resolvido pelos futuros professores durante a formação, momento em que eles tiveram a oportunidade de vivenciar essa metodologia de ensino e aprendizagem nas aulas de Matemática. 
DOI: http://dx.doi.org/10.33238/ReBECEM.2019.v.3.n.1.21905

Quadro 2: Problema resolvido pelos futuros professores

No primeiro turno de uma escola, na hora da sobremesa, foram distribuídos 30kg de doce para 200 alunos. Se no segundo turno o número de alunos é 150, responda:

a) Quantos quilos de doces deverão ser distribuídos para que cada aluno coma a mesma quantidade de doce?

b) Quanto de doce cada aluno come? Isto é um quociente? Qual?

c) As grandezas são proporcionais? Por quê?

d) Somando os quilos de doces dos dois turnos e os números de alunos desses mesmos turnos e dividindo um total pelo outro, o que dará?

Fonte: adaptação de Tinoco (1996)

O problema teve como objetivo desencadear processos de discussão e (re)construção de conhecimento acerca dos elementos que constituem o conceito de proporcionalidade. Sendo assim, iniciamos a tarefa com uma leitura individual, seguida de uma leitura coletiva do problema, para que pudéssemos esclarecer eventuais dúvidas. Observamos que alguns dos futuros professores tiveram dúvidas; deixamos que questionassem, mas preferimos não responder a todos os questionamentos para não interferir em suas interpretações e resoluções; no entanto, em alguns momentos, o pesquisador precisou intervir para ajudá-los na interpretação do problema. Com as dúvidas esclarecidas, pedimos que o resolvessem individualmente. Alguns resolveram o problema utilizando como método a regra de três. A seguir, uma das resoluções apresentadas para os itens (a) e (b) do problema.

Figura 19: Resolução apresentada por A5

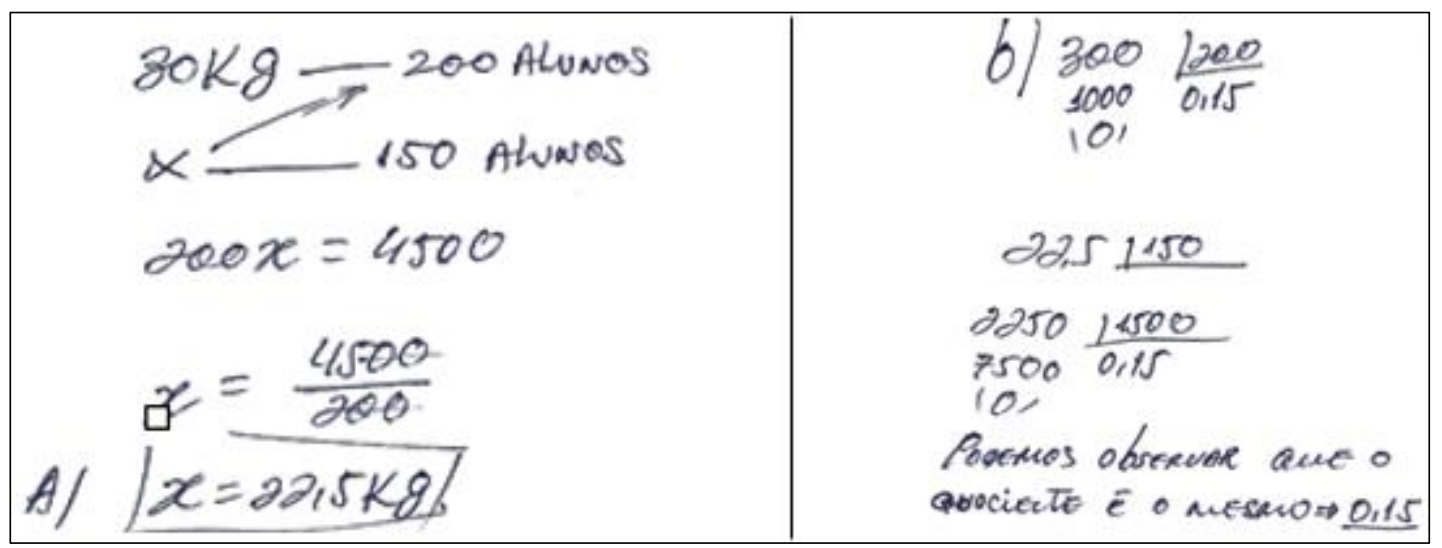

Fonte: Dados da pesquisa

Percebemos na resolução do item "a" que o futuro professor não recorreu à definição de proporção, isto é, não registrou a igualdade entre as duas razões, indo diretamente para a regra de três. Com relação ao item "b", notamos que tanto A5 como os demais licenciandos não responderam com clareza qual é a quantidade de doce que cada aluno come. 
A resposta indica que a quantidade de doce que cada um deve comer é 0,15 e que essa quantidade se refere a um quociente, mas não explicou o que significa esse quociente no problema apresentado e não indicou a unidade de medida $(\mathrm{Kg})$ na resposta.

Outra resolução (item b) que nos chamou a atenção foi a apresentada por A3 pela maneira como o licenciando se expressa, apesar de a solução ter sido a mesma $(0,15)$ apresentada por A5.

Figura 20: Resolução apresentada por A3

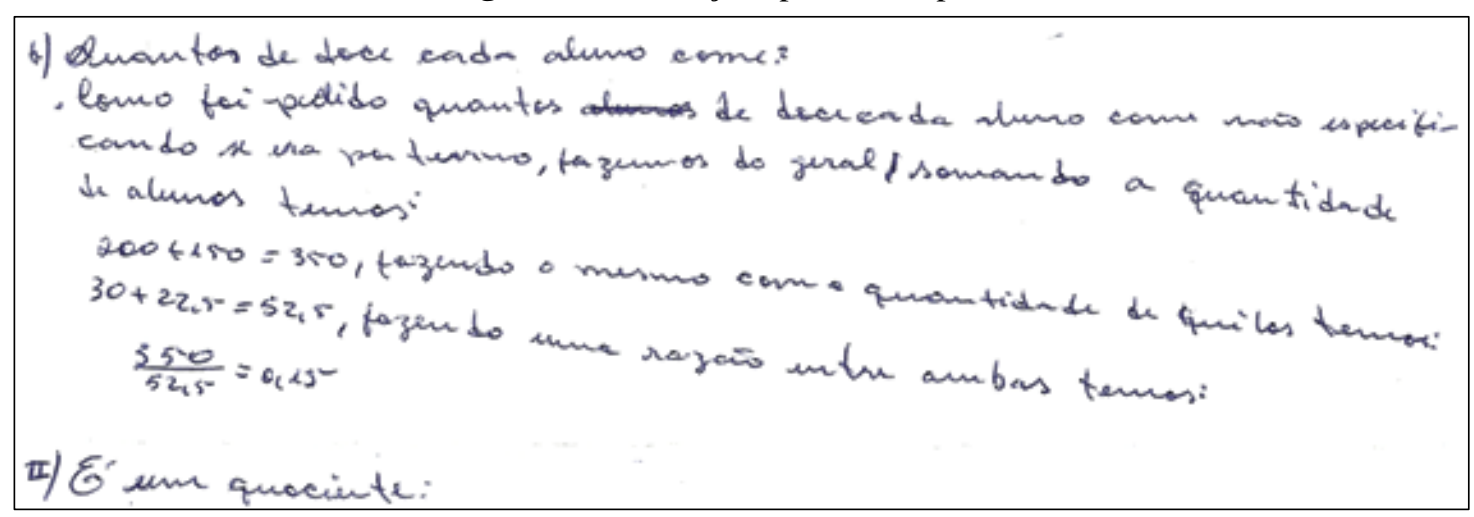

Fonte: Dados da pesquisa

A3 concluiu seu raciocínio dizendo que fazendo a "razão" entre a quantidade de alunos (350) e a quantidade de quilos (52,5), encontra-se 0,15, que para ele, é um quociente. No entanto, ele não explicou o que esse quociente representa no problema.

Observamos, assim, com base na figura 20 que o futuro professor utilizou a linguagem "materna" para a resolução, enquanto que na resolução anterior (Figura 19), destaca-se a linguagem matemática.

Perguntamos (item c do problema) se o problema apresenta uma situação de proporcionalidade, ou seja, se as grandezas são proporcionais. O futuro professor A5, assim como os demais participantes, afirmou que sim; no entanto, ele nos apresentou uma justificativa incompleta ao afirmar que:

Figura 21: Resposta apresentada por A2

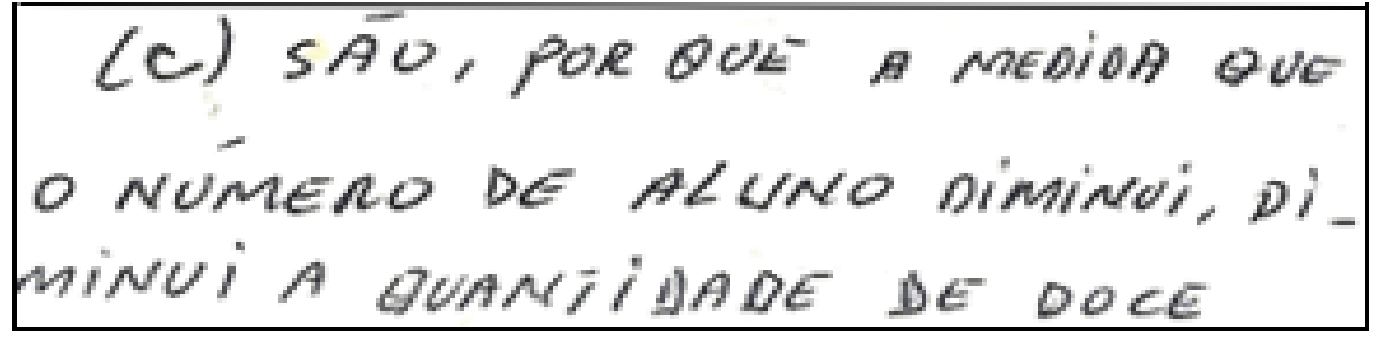

Fonte: Dados da pesquisa 
DOI: http://dx.doi.org/10.33238/ReBECEM.2019.v.3.n.1.21905

Essa justificativa foi apresentada na maioria das respostas. Ela indica que os licenciandos não tinham clareza em relação ao conceito de proporcionalidade. $\mathrm{O}$ fato de "uma grandeza diminuir enquanto a outra também diminui" não é condição suficiente para que ocorra a proporcionalidade.

A falta de clareza por parte dos licenciandos sobre o conceito de proporcionalidade pode ser decorrente da não compreensão do referido conceito matemático, conforme apontam Santos et al., (2005) e Maranhão (2014). Os autores e o documento nos afirmam que é na aprendizagem dos conteúdos que se dá a construção e o desenvolvimento de saberes, principalmente quando há uma integração entre as experiências práticas e a reconstrução teórica desses conhecimentos.

Podemos observar no exemplo a seguir, referente aos preços de assinatura de uma revista, que as duas grandezas diminuem e não apresentam uma situação de proporcionalidade.

Quadro 3: Preços de assinatura de uma revista

\begin{tabular}{|l|l|}
\hline Revista “Olhe só” \\
\hline Duração (meses) & Preço (reais) \\
\hline 12 & 120,00 \\
\hline 6 & 63,00 \\
\hline
\end{tabular}

Fonte: Costa (2012)

Ao final, no item (d), perguntamos: "Somando os quilos de doces dos dois turnos e os números de alunos desses turnos e dividindo um total pelo outro, o que dará?" Os estudantes também encontraram a mesma solução, 0,15. No entanto, A5 concluiu que nessa solução $(0,15)$, o quociente é a proporção:

Figura 22: Resoluções apresentadas por A5 e A15, respectivamente

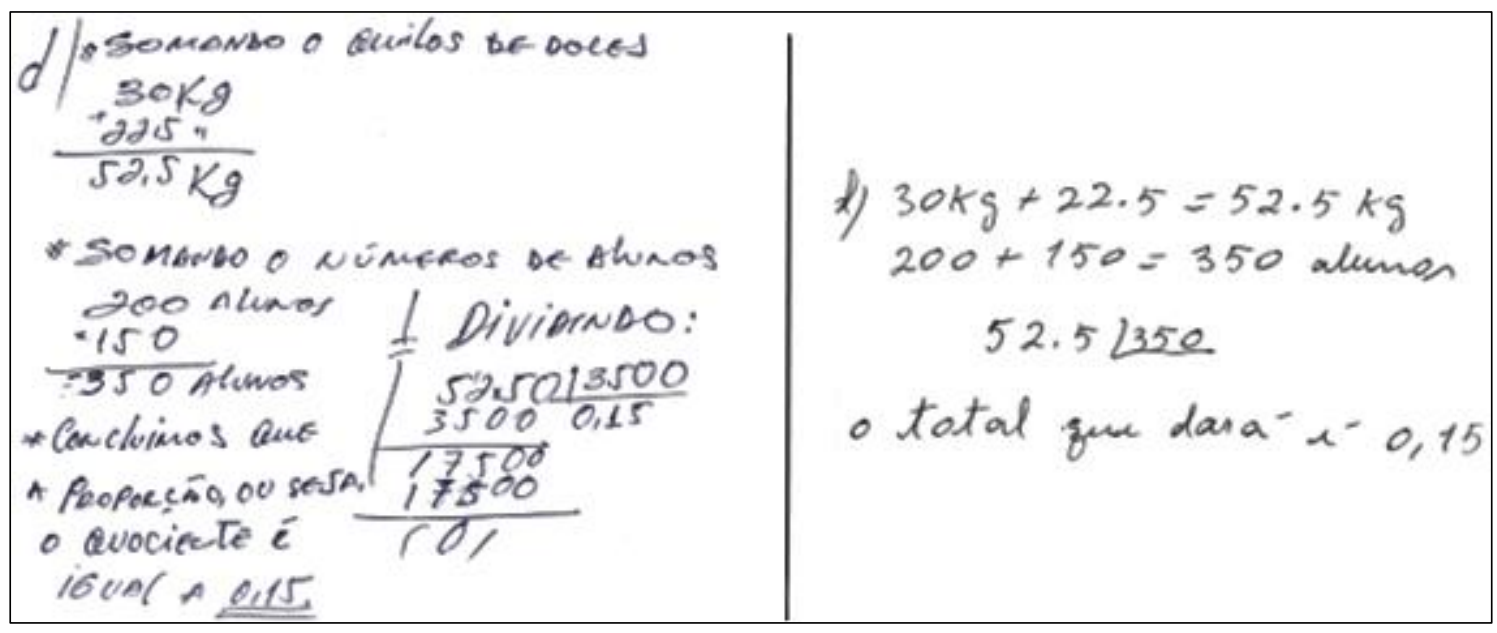

Fonte: Dados da pesquisa 
Além disso, percebemos que eles utilizaram a mesma estratégia de resolução, ou seja, somaram primeiro os quilos de doces, em seguida, as quantidades de alunos, depois fizeram a divisão; contudo, A5 explicou melhor os procedimentos adotados.

Vale ressaltar que, enquanto os licenciandos resolviam o problema, o pesquisador observava, analisava o comportamento de cada um e os incentivava. Em seguida, quando todos já haviam resolvido, entregaram as resoluções escritas ao pesquisador, as quais geraram os protocolos aqui analisados. Então, foi solicitado que cada um registrasse sua resolução na lousa, para que pudéssemos discutir e, com isto, encontrar um consenso quanto aos resultados apresentados, No final do encontro, o pesquisador fez uma apresentação formal e organizada do conteúdo matemático em estudo: proporcionalidade, conforme orientações de Allevato e Onuchic (2014) para a implementação do Ensinoaprendizagem-avaliação através da Resolução de Problemas.

As estratégias utilizadas pelo pesquisador durante e após a resolução dos problemas pelos licenciandos (as observações, as discussões das resoluções e a formalização do conteúdo) vão ao encontro do que é proposto pelo NCTM (2014). De acordo com o documento, para que a aprendizagem matemática aconteça de fato, o professor deve utilizar diversas estratégias de ensino e analisar cuidadosamente o que os alunos fazem, promovendo a aprendizagem de modo que os problemas possam servir de orientação e veículo para a construção dos conceitos e procedimentos matemáticos e para a compreensão de suas conexões. Nesse contexto, a resolução dos problemas apresentados permitiu essa construção.

\section{Reflexões finais}

Apesar das dificuldades, nossa experiência na formação foi muito rica. Pudemos perceber que, através da metodologia de ensino que adotamos (a Resolução de Problemas) para o desenvolvimento das atividades, que os futuros professores puderam vivenciar uma nova maneira de trabalhar a Matemática em sala de aula, pois as atividades são centradas nos problemas, ou seja, o problema é o ponto de partida para o ensino, a aprendizagem e a formalização de um determinado conteúdo.

Eles não estavam familiarizados com esse tipo de abordagem nas aulas de Matemática, em que pensar, resolver problema e comunicar suas estratégias são ações para a construção da aprendizagem matemática, bem diferentes de resolver uma lista de 
DOI: http://dx.doi.org/10.33238/ReBECEM.2019.v.3.n.1.21905

exercícios repetitivos, muitas vezes sem significados para muitos deles. Além disso, eles puderam perceber que a Resolução de Problemas favorece um ambiente de aprendizagem onde o aluno desenvolve-se ativamente, e experimenta avanços na construção do conhecimento. Dessa forma, acreditamos que a formação proporcionou aos licenciandos momentos de construção de conhecimento, tornando-os reflexivos acerca de seus conhecimentos e co-construtores de sua aprendizagem.

Sugerimos, por fim, aos futuros professores que, durante o ensino formal dos conteúdos matemáticos, escolham de forma criteriosa os problemas a serem apresentados aos alunos, para que aprendam a resolvê-los e, progressivamente lhes sejam apresentados problemas mais complexos, para a compreensão da natureza do conteúdo em estudo.

\section{Referências}

ALLEVATO, N. S. G.; ONUCHIC, L. R. Ensino-Aprendizagem-Avaliação de Matemática: Por que através da Resolução de Problemas? In: ONUCHIC, L. R. et al. (org). Resoluçãa de Problemas: Teoria e Prática. Jundiaí: Paco Editorial, 2014. p. 35-52

BASTOS, A. S. A. M. Análise de erros matemáticos na resolução de problemas aplicados à física elétrica. 2012. Tese (Doutorado em Ensino de Ciências e Matemática) - Universidade Cruzeiro do Sul, São Paulo, 2012.

BRASIL. Ministério da Educação. Parâmetros Curriculares Nacionais - Matemática $1^{\circ}$ e $2^{\circ}$ ciclos: Matemática. Brasília: MEC, 1998.

BRASIL. Ministério da Educação. Conselho Nacional de Educação. Resolução. Parecer CNE/CP 09/2015. Define as Diretrizes Curriculares Nacionais para a formação inicial em nível superior (cursos de licenciatura, cursos de formação pedagógica para graduados e cursos de segunda licenciatura) e para a formação continuada. Brasília: MEC, 2015.

COSTA, M. S. Ensino-aprendizagem-avaliação de proporcionalidade através da resolução de problemas: uma experiência na formação inicial de (futuros) professores de matemática. 2012. Tese (Doutorado em Ensino de Ciências e Matemática) - Universidade Cruzeiro do Sul, São Paulo, 2012.

COSTA, M. S.; ALLEVATO, N. S. G. AVALIAÇÃO: um processo integrado ao ensino e à aprendizagem de matemática através da resolução de problemas. Acta Scientiae, Canoas, v. 17, n. 2, p. 1-17, 2015.

CURI, E. A matemática e os professores dos anos iniciais. São Paulo: Musa Editora, 2005.

CYRINO, M. C. C. T. Formação de professores que ensinam matemática em Comunidades de Prática. In: CONGRESO IBEROAMERICANO DE EDUCACIÓN MATEMÁTICA, 7., 2013, Montevideo. Actas del VII CIBEM. Montevideo: FISEM, 2013. v. 1. p. 5188-5195. 
DELORS, J. (org.). Educação, um tesouro a descobrir. Relatório para a Unesco da Comissão Internacional sobre Educação para o século XXI. São Paulo: Cortez; Brasília: MEC; Unesco, 1999.

FERNANDES, D. et al. Resolução de Problemas na Formação Inicial de Professores de Matemática. In: FERNANDES, D.; LESTER, F.; BORRALHO, A.; VALE, I. (org.). Resolução de problemas na formação inicial de professores de matemática: múltiplos contextos e perspectivas. Aveiro: GIRP, 1997. s.p.

FIORENTINI, D.; LORENZATO, S. Investigações em educação matemática: percursos teóricos e metodológicos. 3. ed. rev. Campinas: Autores Associados, 2012.

GARCIA, C. M. Desenvolvimento profissional docente: passado e futuro. Sísifo / Revista de Ciências da Educação, Lisboa, n. 8, p. 7-21, 2009.

GATTI, A. B. Formação de professores: condições e problemas atuais. Revista Internacional de Formação de Professores (RIFP), Itapetininga, v. 1, n. 2, p. 161-171, 2016.

HELDER, R. R. Como fazer análise documental. Porto, Universidade de Algarve, 2006.

KRULIK, S.; RUDNICK, J. A. Roads to Reasoning - Developing Thinking Skills Through Problem Solving, Chicago: McGraw-Hill, 2002.

LÜDKE, M.; ANDRÉ, M. E. D. A. Pesquisa em educação: abordagens qualitativas. São Paulo: EPU, 2017.

MARANHÃO (Estado). Diretrizes Curriculares / Secretaria de Estado da Educação, SEDUC, 3. ed. São Luís, 2014.

NATIONAL COUNCIL OF TEACHERS OF MATHEMATICS (NCTM). Princípios para a Ação: assegurar a todos o sucesso em Matemática. Tradução de Fernando Nunes. Lisboa: APM, 2014.

NUNES, C. B. O Processo Ensino-Aprendizagem-Avaliação de Geometria através da Resolução de Problemas: perspectivas didático-matemáticas na formação inicial de professores de matemática. 2010. Tese (Doutorado em Educação Matemática) - Instituto de Geociências e Ciências Exatas, UNESP, Rio Claro, 2010.

ONUCHIC, L. R. Ensino-Aprendizagem de Matemática através de Resolução de Problemas. In: BICUDO, M. A. V. (org.) Pesquisa em Educação Matemática: Concepções e Perspectivas. São Paulo: Editora UNESP, 1999.

ONUCHIC, L. R.; ALLEVATO, N. S. G. Pesquisa em Resolução de Problemas: caminhos, avanços e novas perspectivas. BOLEMA, Rio Claro, v 25, p. 73-98, 2011.

PERRENOUD, P. A Formação dos Professores no Século XXI. In: PERRENOUD, P. et al. (org.). As Competências Para Ensinar no Século XXI: a formação dos professores e o desafio da avaliação. Tradução: Claudia Schilling; Fátima Murad. Porto Alegre: Artmed Editora, 2002, p. 11-33.

PIMENTA, S. G. Formação de professores: identidade e saberes da docência. In: PIMENTA, S. G. (org.). Saberes pedagógicos e atividade docente. 6. ed. São Paulo: Cortez, 2008. p. 15-34. 
DOI: http://dx.doi.org/10.33238/ReBECEM.2019.v.3.n.1.21905

PIRES, C. M. C. Reflexões sobre cursos de Licenciaturas em Matemática, tomando como referências as orientações propostas nas Diretrizes Curriculares Nacionais para a formação de professores da Educação Básica. Educação Matemática em Revista, São Paulo, n. 11-A, edição especial, p. 44-56, abr. 2002.

PONTE, J. P. A vertente profissional da formação inicial de professores de Matemática. Educação Matemática em Revista, São Paulo, n. 11A, edição especial, abril, 2002.

SANTOS, L. et al. A Matemática na Formação Inicial dos Professores: documento para discussão. Lisboa: APM, 2005. Disponível em http://www.apm.pt/file/-

Matemática_na_formação_Inicial_Professores_47544a39aab76.pt. Acesso em: 25 abr. 2018.

SERRAZINA, L.; OLIVEIRA I. O professor como investigador: Leitura crítica de investigações e educação matemática. In: GTI - Grupo de Trabalho de Investigação: Reflectir e investigar sobre a prática profissional. Lisboa: APM, 2002. p. 283-308.

SHULMAN, L. S. Disciplinas de investigação em educação: uma visão nova. Métodos complementares para a pesquisa em educação. Ed. Richard M. Jaeger. 2. ed. Washington, DC: American Educational Research Association, 1997.

TARDIF, M. Saberes docentes e formação profissional. 16. ed. Petrópolis: Vozes, 2014.

TINOCO, L. A. A. (coord.) Razões e Proporções. Instituto de Matemática / UFRJ - Projeto Fundão - SPEC/PADCT/CAPES - Rio de Janeiro: Editora UFRJ, 1996.

VALE, I. Desempenhos e concepções de futuros professores de Matemática na resolução de problemas. In: FERNANDES, D.; LESTER, F.; BORRALHO, A.; VALE, I. (org.). Resolução de problemas na formação inicial de professores de matemática: múltiplos contextos e perspectivas. Aveiro: GIRP, 1997. p.1-38.

VAN DE WALLE, J. A. Matemática no ensino fundamental: formação de professores e aplicação em sala de aula. Tradução de Paulo Henrique Colonese. 6. ed. Porto Alegre: Artmed, 2009.

Recebido em: 11 de março de 2019.

Aceito em: 17 de abril de 2019. 